\title{
Performance Measures and Technical Services: Efficiency and Effectiveness
}

\author{
Karen S. Croneis and Linda H. Y. Wang
}

Librarians are currently using performance measures to evaluate services. Because libraries are complex organizations with many interrelated departments, any evaluation of public services activities is also an implicit evaluation of technical services policies and procedures. Therefore, it is important for technical services librarians to be familiar with the concepts of performance measurement.

\section{Efficiency and Effectiveness}

Historically, the two components of evaluation have been efficiency (doing things right) and effectiveness (doing the right things). These two exist in an inverse relationship, that is, increased efficiency generally results in decreased effectiveness. For example, providing fewer access points may speed up cataloging but it also tends to decrease the user's chances of finding information.

F. W. Lancaster ${ }^{1}$ has declared that, theoretically at least, technical services can be evaluated from two viewpoints. The first deals with internal efficiency.

As production units, technical services have valued efficiency and based their evaluations on that fact. Cost and productivity have been the primary considerations in evaluating internal efficiency. Technical services librarians have well documented their success as efficiency experts. There are many studies on a wide variety of technical services activities: time studies, costbenefit analyses, vendor and systems evaluations, and others.

Lancaster also posits evaluation based on effectiveness, that is, on the long-range effect that technical services have on the public services of the library. The title of an excellent book, Cost Effective Technical Services, provides an example

\footnotetext{
Karen S. Croneis is head of the Physics-Mathematics-Astronomy Library at the University of Texas at Austin. Linda H. Y. Wang is Reference Librarian at the University of South Alabama, Mobile.
}

of how easily the two concepts of efficiency and effectiveness can be confused. Papers and case studies examined cost-efficiency (doing things more inexpensively) without a corresponding discussion of effectiveness. The question "Is this the right thing to do?" was generally not addressed.

Few studies examine the effectiveness of technical services, that is, their impact on public services. Granted, the number of studies on information-seeking behavior, book availability, and document delivery have increased significantly in the last fifteen years. These have not been as widely discussed in the traditional technical services literature because of the technical/public split.

Activities involving users have been seen as strictly "public services" issues and, therefore, "not technical services" issues. Likewise, "technical" equals "not public." Again, effectiveness has been the domain (and the problem) of public services while technical services have been concerned with efficiency.

This efficiency/effectiveness discussion has also been phrased in terms of quantity/quality. In discussing the trade-offs inherent in technical services, Carol Mandel concludes, "A formal and quantitative approach to analyzing questions of quality and productivity in technical services will result in a net benefit to library users." ${ }^{2}$

\section{User Groups}

To be valid indicators of library effectiveness, performance measures must incorporate user data. ${ }^{3}$ Recognizing that users are individuals whose information demands may not match their information needs, the first step in using performance measures is to identify broad-based user groups.

When the term "user group" is mentioned, most technical services librarians think of a vendor- or system-based user group (e.g., NOTIS User Group, Music OCLC User Group). In the 
context of performance measures, however, the term "user group" refers to the people who "use" the results of the complex set of activities called technical services (acquisitions, cataloging, serials control, physical processing, binding, and preservation),

Technical services librarians have at least three user groups - the general public, public services librarians, and network users.

The first group consists of the "public," the well-defined group (or groups) of people who use a particular library for a particular reason. Most libraries create promotional and informational pieces that list various services targeted to specific market groups.

The second group of users that technical services librarians serve are the other staff members, primarily the public services librarians, at their own institutions. While the information needs of these two groups are different, they have the same basic demands: timely receipt and processing of materials, and easy access to the information contained therein. In this situation, timeliness can be seen as a measure of efficiency; access, of effectiveness.

Network members constitute a third user group. These people use the data records that technical services people have created and contributed to a cooperative database. The records

\section{... any evaluation of public} services activities is also an implicit evaluation of technical services policies and procedures.

might be used for shared cataloging, acquisitions, interlibrary loan, etc. Technical services librarians can easily identify the needs of this user group, primarily because they are also members of it.

\section{OPAC as Common Ground}

Developing performance measures for these groups is challenging. Within each group are subgroups. Because individuals have many different information needs, they can belong to more than one subgroup. But, in an online environment, nearly all groups will use the online public access catalog (OPAC) to meet their needs. The automated catalog, "the keystone that joins the two areas of technical and public services, ${ }^{n}$ is changing the way people use libraries. New user behaviors and expectations, in turn, are forcing libraries to reevaluate their operations.
In 1985 Barbara Markuson ${ }^{5}$ noted that most of our efforts have been devoted to automating the library and the functions of librarians, not to automating access and retrieval systems for our users. OPACs, like card catalogs, are windows on collections and gateways to information. As such, an OPAC must be evaluated in terms of the information it contains, how easy it is to use, and how effective it is.

\section{Catalog Use}

Research on catalogs generally falls into two areas: catalog use studies and catalog user studies. In their informative 1983 review article on catalog use studies, Pauline Cochrane and Karen Markey ${ }^{6}$ categorized the questions regarding online catalogs and then identified successful methodologies for studying each category. In doing so, they provided a framework that continues to serve as well.

Users expect, quite justifiably, that an OPAC will provide at least as much information or access as the card catalog. Gunnar Knutson? compared an online catalog with an existing card catalog to detect levels and types of errors on four access points: names, titles, series, and subjects. The online catalog had a lower failure rate in all areas except series. Knutson checked 200 bibliographic records with 905 online access points and found 23 errors, an overall error rate of 2.54 percent. Using Knutson's figures to extrapolate for 500,000 records, one would expect to find $2,262,500$ online access points and about 57,500 errors, a raw number that most librarians and users would find absolutely unacceptable.

Consistency studies (subject cataloging and classification) and availability studies can give useful performance measures. In a recent study based on Paul Kantor's availability analysis, Deborah Barreau ${ }^{8}$ identified four catalog problems that are most likely to interfere with patron success with the OPAC: (1) incomplete location information on the bibliographic record; (2) incomplete holdings information in the database; (3) special characters and punctuation in the index fields that were interpreted incorrectly by the search program; and (4) inadequate access points and display of fields in the default format. The terms "incomplete," "incorrect," and "inadequate" underline the fact that quality control is essential. Performance measures can be useful in quality control situations.

\section{Catalog Users}

Charles Hildreth" has pointed out that "the 
online catalog stands apart from earlier catalogs because it is interactive, infinitely expandable, and public." There is no question about the potential of the online catalog as a tool for rapid, convenient, and comprehensive research.

Unfortunately, there is little evidence that searching an OPAC (as opposed to a card catalog) increases a user's success in finding information. Cochrane and Markey ${ }^{10}$ also concluded that "how the user and system interact is the important thing, not that the interaction occurs 'online'."

Studies of catalog users have focused on information-seeking behaviors but no conceptual model of user behavior has been developed. Until that time, data will still be only indicative and situation-specific.

Patrons use online catalogs differently from the way they use card catalogs, particularly for subject searching. In a recent study, Micheline Hancock ${ }^{11}$ found that users adapt their search to the structure of the tools available. A major obstacle to effective subject searching may lie in the lack of interaction among the indexing language, the classification scheme, and the actual titles.

Simply put, query terms generated by users do not match catalog subject entries. The likelihood that any two people will use the same term for a concept or a book, or that a searcher and an information system will use the same term for a concept, ranges from ten to twenty percent. ${ }^{12}$

Understanding the information-seeking behavior of users is crucial in designing an online catalog that complements the search strategies of its users. Because OPACs are "public," search strategies can be recorded on transaction logs, examined and analyzed to determine what it is that users actually do in the search process. Success can be noted and problems identified. In one recent project, Thomas Peters ${ }^{13}$ found failure rates (defined as those searches that produced zero hits) of approximately forty percent for all types of searches.

From such studies, librarians can establish baseline data and then compare those numbers with future performance measurements. Peters suggests that librarians use the information to develop bibliographic instruction programs and design OPAC teaching sessions that address the most prevalent problems. Bibliographers would be interested in summaries of the types and subjects of materials sought by OPAC users, both items in the database (for possible duplication) and items not in the database (for addition to the collection).

Marcia Bates ${ }^{14}$ urges librarians to rethink subject cataloging in an online environment. Access should be determined by the total mix of pre-existing and added "search capability" indexing. This "superthesaurus" would be designed and geared to the needs of users rather than indexers. A very active area of current research is the examination of expanded subject headings based on systems such as the Library of Congress, Dewey Decimal Classification, and PRECIS.

Clearly, today's technical services librarians are, or will become, database managers and providers of value-added services. In the future, "information resources will be almost seamlessly interfaced so that the public has direct, timely, and effective access to what it needs to know." ${ }^{15}$

It is the librarians's job to state in quantitative, measurable terms what "direct, timely and effective access" is. "Direct" might translate into finding an item in the owning library ninety percent of the time. "Timely" would depend on circulation status; ninety-eight percent of the time, a user would have an item from interlibrary loan within ten days. "Effective" might mean that ten percent of the time a user gets zero hits on a subject search on the library's OPAC. Unreasonable? Maybe. But identifying the current levels of service, setting goals, and monitoring progress is what performance measures can do.

Some performance measures already exist and others are needed. Ideally, these can be developed by teams of technical and public service librarians who bring their own perspectives and expertise to an evaluation project.

\section{Conclusion}

Technical services' discomfort with effectiveness mirrors public services' uneasiness with efficiency. As OPACs are transforming the way people use libraries, they are also changing the relationship between technical and public services.

In 1986 Gillian McCombs ${ }^{16}$ suggested that, in ten years (that is, by 1996), an evaluation of library services would become "mainly an evaluation of the information provided on the VDT screen - how much of it is there, how easy it is to obtain and how quickly." Perhaps her prediction is more accurate than some would like to admit.

Our shared mission as technical and public services librarians is to provide access to information. Using performance measures and other evaluation techniques, we can find ways to serve our users more efficiently and more effectively. 


\section{References}

1. F. W. Lancaster, The Measurement and Evaluation of Library Services (Washington, D.C.: Information Resources Press, 1977), 264.

2. Carol A. Mandel, "Trade-offs: Quantifying Quality in Library Technical Services," Journal of Academic Librarianship 14 (September 1988): 220.

3. Ronald R. Powell, The Relationship of Library User Studies to Performance Measures: A Review of the Literature, University of Illinois Graduate School of Library and Information Science Occasional Paper, Number 181 (Urbana-Champaign, Ill.: University of Illinois, January 1988), 22-23.

4. Caroline Arms, "The Technological Context," in Campus Strategies for Libraries and Electronic Information, ed. Caroline Arms. EDUCOM Strategies Series on Information Technology (Bedford, Mass.: Digital Press, 1990), 13.

5. Barbara Evans Markuson, "Issues in National Library Network Development: An Overview," in Key Issues in the Networking Field Today, Proceedings of the Library of Congress Network Advisory Committee Meeting, May 6-8, 1985. Network Planning Paper No. 12 (Washington, D.C.: Library of Congress, 1985) 9-32. 6. Pauline A. Cochrane and Karen Markey, "Catalog Use Studies - Since the Introduction of Online Interactive Catalogs: Impact on Design for Subject Access," Library and Information Science Research 5 (1983): 337-363.
7. Gunnar Knutson, "A Comparison of Online and Card Catalog Accuracy," Library Fesources and Technical Services 34 (January 1990): 24-35.

8. Deborah K. Barreau, "Using Performance Measures to Implement an Online Catalog," Library Resources and Technical Services 32 (October 1988): 312-322.

9. Charles R. Hildreth, "Beyond Boolean: Designing the Next Generation of Online Catalogs," Library Trends 35 (Spring 1987): 647-667

10. Cochrane and Markey, "Catalog Use Studies," 361.

11. Micheline Hancock, "Subject Searching Behavior at the Library Catalogue and at the Shelves: Implications for Online Interactive Catalogs," Journal of Documentation 43 (December 1987): 303-321.

12. Marcia J. Bates, "Rethinking Subject Cataloging in the Online Environment," Library Resources \& Technical Services 33 (October 1989): 400-412.

13. Thomas A. Peters, "When Smart People Fail: An Analysis of the Transaction Log of an Online Public Access Catalog," Journal of Academic Librarianship 15 (November 1989): 267-273.

14. Bates, "Rethinking Subject Cataloging," 400-412.

15. James W. Dwyer, "The Evolutionary Role of Technical Services," Journal of Library Administration 9 (1988): 13-26. 16. Gillian McCombs, "Public and Technical Services: Disappearing Barriers," Wilson Library Bulletin 61 (November 1986): $25-28$.

\section{BROADFOOT'S}

North Carolina Book Sellers Helping North Carolina Librarians

\section{Broadfoot's of Wendell}

6624 Robertson Pond Rd. • Wendell, NC 27591 • (919) 365-6963

The largest selection of North Carolina books anywhere

Free Catalog Cards - Same Day Shipment

Catalog on request

\section{Broadfoot Publishing Company}

Route 4, Box 508-C • Wilmington, NC 28405 • (919) 686-4379

Publishers of historical and genealogical reference sets. Now reprinting North Carolina Troops - Volumes I-VII

Catalog on request 